Gablas, B., Ruzicky, E., Ondrouchova, M. (2018). The Change in Management Style during then Course of a Project from the Classical to the Agile Approach. Journal of Competitiveness, 10(4), 38-53. https://doi. org/10.7441/joc. 2018.04 .03

\title{
THE CHANGE IN MANAGEMENT STYLE DURING THE COURSE OF A PROJECT FROM THE CLASSICAL TO THE AGILE APPROACH
}

\section{- Branislav Gablas, Eugen Ruzicky, Martina Ondrouchova}

\begin{abstract}
Changing managing style in the middle of a project cycle has become a highly discussed topic. Most business enterprises consider it a risky process and therefore resist doing it. In our research, we aim to test the possibility of changing management style in the course of a project from a theoretical point of view. Normally, the classic waterfall is considered as an obvious project management style, while a change would mean a shift to the agile management style. Switching between the classic and agile management style during one project is an area which needs deeper consideration. Since there is a lack of documented samples, a questionnaire was prepared to determine if this switch is possible. The data were collected through an anonymous online survey and controlled by the 4 level scale to avoid concentration in a medium answer (5 Likert scheme). Taken mainly from SMEs, the survey results show that there is a positive overall sign that a transition between classic and agile management style over the project life cycle is possible, but only in the areas suitable for agile management. By analyzing the 119 responses of project managers and using the Fisher's exact test, we have shown that it is possible to change management style during a project. The change increases the competitiveness of SMEs in order to determine how to proceed in the implementation of projects. The research should continue with the monitoring of a real project which is undertaking the switch from the classic to the agile approach.
\end{abstract}

Keywords: waterfall management style, agile management style, changes in the course of the project life cycle, business environment, PRINCE2, PMI, Scrum, classic, project, manager, SME businesses JEL Classification: M11, M12, M14

Received: July, 2018

1st Revision: October, 2018

Accepted: October, 2018

\section{INTRODUCTION}

In the past twenty years, substantial changes have come about in project management. From classical project management styles such as PRINCE2 and PMI, new agile methods have been launched for project management such as PRINCE2 Agile and SCRUM (see book Chin, 2004; Kaliprasad, 2005). Over the past five years, we have sought to determine risks and actions that may arise as an all agile software development team moves toward agile methods (Thiemich, 2013; Orlowski et al., 2017; Meding, 2017; Saito et al., 2018). Gradually, the experience of soft- 
ware projects is transferred to other types of projects using techniques for designing, developing, communicating, and tracking progress (Paredes et al.,2014; Tomanek et al., 2014;). Current research on the transformation to agile project management has been explored mainly in cases in which an entire project team which had been working in a classic environment has implemented agile methods from the beginning to the end of the project. The question is whether it is possible to switch as classic project management is taking place to agile approaches. From our surveyed sample of project managers' replies $(\mathrm{N}=119)$, this appears to be possible, especially for medium-sized projects within SMEs. On the other hand, the strategy of any enterprise involves the development and implementation of innovative ideas in the form of projects. New ways to improve project management have the greatest chances for SMEs in cases in which re-training a substantial team is feasible. Seeking ways by which industrial engineering can reduce costs and increase business performance (Rajnoha et al., 2018; Ključnikov et al., 2016) is also related essentially to agile methods. By using the Chi-square and Fischer's exact test, mostly based on management responses from SMEs, we have theoretically shown that it is possible to change the management style of a project from the classic to agile approaches.

The aim of our research is to test the possibility of changing management style in the course of a project and determine whether a change in the management style is possible in the course of project life. The research is focused on the classic management style, which encompasses deeper control over all project aspects. When considering the method of project management, aspects like the project type, budget size, duration of the project, preferred customers, quantity and extent of expected changes, the urgency with which the product is required, knowledge, skills, along with the experience of management and staff from similar projects are all highly valuable.

\section{LITERATURE REVIEW}

The concept of project has been defined using various concepts by different organizations such as IPMA, PMI and ISO (IPMA, 2006; PMI, 2013; ISO, 2012). A research currently being conducted has shown that, mainly due to globalization, there is a significant increase in the performance of project management methods and tools by organizations (Too \& Weaver, 2013). Project management is a powerful instrument for accomplishing the planned purposes of an organization's execution and control of activities in a systematic order (Mir \& Pinnington, 2014). Several researches have been carried out on how the projects can contribute to the process of value/output creation (see Thomas \& Mullay, 2007; Winter \& Szczepanek, 2008; Lechler \& Cohen, 2009) but there have been far fewer researches on the application of change management, particularly changes in management style during a project life cycle. It should be noted that a period of functional organizations based on a structure with different levels of departments where the head of the department closely directs his/her staff and checks the tasks being performed is almost over. Nowadays, staff will most likely work in a team composed of different professions aiming to achieve common goals. Team members will participate in the project until its successful completion. Therefore, the focus on the project management and project manager's competencies must fall within the core interest of company managers. This means that management of projects implies constantly risks monitoring, resources optimization, taking care of contractual relations, 
dealing with multi-criteria decision-making, and constantly being aware of changes. The project manager must transparently allocate resources to be used efficiently. He/she must solve various problems that naturally arise from the use of these resources while striving to fulfill the requirements of the project sponsor with respect to time schedule and budget constraints, e.g. as indicated by Kerzner in 2004. Project management as a concept was developing and knowledge was being accumulated regarding agile methods of management when the SCRUM method was brought out as a new style of project management (Machal et al., 2017). The agile style of project management is interactive and flexible. Throughout the years, agile methods have been used in many project cases and are not only bound with programming in the IT sector. The successful management of change is crucial to any organization in order to survive and succeed in the present highly competitive and continuously evolving business environment (Todnem, 2007). Generally, changes in management have been the subject extensive research (Boonstra, 2004; Jashapara, 2004; De Witt, 2017). Change occurs in different forms; incremental change, management adjustments, discontinuous change and reactive change. Moran and Brightman refer to management change as a continuous renewal of direction, structure, and capabilities in order to serve the dynamic needs of customers. When an organization prepares a project, a decision on project management and the extent to which a standard of project management will be applied is vital. It can be argued that the project management style should not change as it is related to project documentation, team composition and qualifications, supplier contracts and customer expectations. However, as Cummings (2004) indicates, organizations are under highly competitive demands to yield quicker and effective performances at reasonable costs and higher quality, thus a change in management style can foster more efficient and effective enterprise performance.

\section{THEORETICAL BACKGROUND}

\subsection{Classical (waterfall) approach to the project management}

Standard project cycles involve five phases, including initiation, planning, execution, control, and closing. Since some stages might overlap, we have limited the delineation to three cycles, initiation and planning, execution and control, and, finally, closing. Our analysis will be based on the PRINCE 2 components of management style (Bentley, 2010). However, we shall include aspects of other PMI strategies (PMI, 2013) to complement the PRINCE 2 towards a projection of a real project situation. These two sources lay down basic project assumptions in the classical approach of project management:

- The organizational structure of the project - the organization of project has a classic threestep structure within the project steering committee, i.e. the executive/s, senior suppliers and senior users. In other projects, the role of the project committee may be replaced by sponsor responsibility. The success of the project depends on the steering committee. Another level is the project manager who supported by project support, with the lowest level represented by the project teams.

- Project schedule and control of performance - a document is created that controls the progress of a project and describes how to achieve its objectives. The project plan is divided 
into stage plans, each of which represent a contract between the project committee and the project manager to achieve the stage objectives. Any deviation from the agreed tolerance of the plan results in failure.

- Making changes - in classical project management, changes introduce a negative element that will require additional administrative efforts and usually also extra costs. Such a negative influence on time and costs is usually eliminated by change prevention activities. However, the most important factor is that the customer receives everything he/she wanted at the beginning of the project within a defined time and scope (even also at the end of the project). Furthermore, a change might be initiated in which the customer changes his/her expectation any time during the project execution. This alteration might prove fatal when the classical management style of projects is in the process of being implemented. The difference between the classical and agile environment is manifested in the approach to management change in these situations.

\subsection{Agile approach to the project management}

The agile approach in project management is derived from methods used for software development which enable quick adaptations in the incremental development a product. Throughout the years, agile methods have found their place in management style mainly due to their flexibility, dynamics, and effectivity. The system of agile approach was instituted in 2001 when the Agile Manifesto of software development was introduced in Utah. In 2018, the Manifest Agile Alliance determined the basic values of agile management:

- Individuals and interactions over processes and tools.

- Working software over comprehensive documentation.

- Customer collaboration over contract negotiation.

- Responding to a change-over following a plan.

The principles of the Agile Manifesto are as follows:

- Our highest priority is to satisfy the customer through the early and continuous delivery of valuable software.

- Welcome changing requirements, even late in development. Agile processes harness change for the customer's competitive advantage.

- Deliver working software frequently, from a couple of weeks to a couple of months, with a preference to the shorter timescale.

- Business people and developers must work together daily throughout the project.

- Build projects around motivated individuals.

- Give them the environment and support they need and trust them to get the job done.

- The most efficient and effective method of conveying information to and within a development team is a face-to-face conversation.

- Working software is the primary measure of progress. 
- Agile processes promote sustainable development.

- The sponsors, developers, and users should be able to maintain a constant pace indefinitely.

- Continuous attention to technical excellence and good design enhances agility.

- Simplicity - the art of maximizing the amount of work not done is essential.

- The best architectures, requirements, and designs emerge from self-organizing teams.

- At regular intervals, the team reflects on how to become more effective, then tunes and adjusts its behavior accordingly.

\subsection{Changing the project management style}

In most cases, changing management style while the project is running is very unlikely. Instead, problems are resolved by closing the current project. Hsieh and Wu (2004) lay out some reasons that will drive an organization to change the management style in the middle of a project:

- a customer completely changing the policy of project management or when an acquisition by the company using the agile management is received,

- when the classical project management has proven to be cumbersome, and the project is obviously not achieving its intended goals,

- when the project was badly prepared, and many changes are being requested,

- when a project is under a significant time delay with a fixed delivery time.

The determining factor in agile management is the general acceptance of the idea that the customer will not get absolutely everything he/she wants. It should be remembered that the introduction of the agile management is not just a senior management decision, but it also represents a change in the thinking of the project team members and organizational approach to project management. Several sources (Lavazza \& Valetto, 2000 or Hayes, 2014) determine steps to be taken during the change of management style, i.e. campaigns within a company to obtain agreements and support from relevant stakeholders and team members:

- Evaluate the current situation and get an overview of finished deliveries as well as work out the current product status of resources for the project.

- Define key delivery components and create a list of all required components.

- Prioritize all remaining project delivery components as well as their realization time and financial appreciation.

- Calculate the time and cost of completing the project with the limitations currently applicable to the project.

- Decide whether the project will bring value to the updated business case.

- Create or update project structures. Create a new release plan and get approval from the customer.

Little documentation on the change in the management style in the middle of a project cycle exists. This might be attributed to the risks involved in making such a decision. Burnes \& Jackson 
(2011) claim that substantial evidence indicates $70 \%$ of all changes in management initiatives fail. This claim is, however, disputed by Hughes (2011), who finds no valid empirical evidence to support this statistic. Bennebroek \& Veld (2004) associate a number of challenges involved in focusing on a single aspect rather than the whole process and the dominant management system as well as focusing on content-driven actions. Furthermore, Kotter \& Schlesinger (2008) associate failure with resistance. They point out that resistance may arise due to self-interest, a lack of trust, misunderstanding and a low tolerance for change. In most cases, the success of changes in management style is likely to be realized when the process is initiated sooner. In our research, however, we consider the style change in a situation in which about $60 \%$ of the sources have been spent. Since we examine the change with respect to a project cycle, we will consider components such as the project organizational structure, planning, the scope of delivery, project documentation and reporting. To conclude, we have to mention that there are also cases when switching from the classical to agile style is impossible in practice. Among the main obstacles, we may include cases such as:

- When the type of a project and nature of delivery does not allow agile management. A typical example can be a building construction project.

- Disapproval from the senior management of a customer organization exists.

- Members of the steering committee and project teams have little or no experience in the field of the agile project management.

\section{RESEARCH OBJECTIVE AND METHODOLOGY}

The objective of our research is to test the possibility of changing management style in the course of a project and to determine whether a change in management style in the course of project life cycle is possible. The research is focused on the classic management style, which encompasses deeper control over all project aspects, as well as on the agile management style.

\subsection{Sampling a group of project managers}

In our quantitative survey the variables had been measured to enable the findings to be generalized from a representative sample of registered project managers. The sampling group was randomly taken from the LinkedIn network. Each person participating in the survey was to be an experienced project manager as described in the sampling person profile. The country, experience, education or other factors were not taken into consideration, as we perceived them as irrelevant to the aim of the survey. During the research, the method of sampling was applied as well as a probability sampling, which was specifically pinned down to a simple random sampling.

There are two ways that sampling members participated in the research:

- reaction to the article published on LinkedIn with a direct link to the survey

- 900 project managers were randomly asked to answer a short questionnaire, some of them from Slovak and Czech SMEs

- 43 responses collected in the first round from June 2017 to December 2017 
- 76 responses collected in the second round from January 2018 to August 2018.

\subsection{Data collection from questionnaires}

The survey included simple data collection from a short questionnaire. Different types of questions we prepared which represented the mixture of closed and open questions while some of them were mandatory. Data collection was done online where the respondents filled an electronic form. We received in total 119 answers from more than 900 questionnaires distributed in two rounds.

A sample of Questionnaire:

- Contact identification: Name, Email, Personal description

- Project management experience: Classic, Agile, Both, None of them

- According to your opinion, is it possible to change the project management style in the course of some projects?: Absolutely not, Rather Not, Maybe yes, Yes for some projects, I have no idea

- Choice description

- Other proposals

\section{Scale of measurement}

The research was done on the shorter scale of the four levels Likert scale (see Norman, 2010). Original seven levels Likert scale was shortened to make questions clear, unambiguous and easy to answer. Also, there is an additional section containing factor questions that allowed the respondents to fill in a text feedback.

\subsection{The Chi-squared test and Fisher's exact test}

The hypothesis was tested on the basis of the P-value method when zero and alternative hypothesis was determined. The zero hypothesis was set as: The change in management style in the course of the project life cycle is not possible $\left(\mathrm{H}_{0}\right)$. The alternative hypothesis was set as: The change in management style in the course of the project life cycle is possible $\left(\mathrm{H}_{1}\right)$. The question in the research was about the possibility of the management style change. The level of significance ( $p$-value) is set at $\alpha=0,05$, which means that the probability of results collected in the research is random and lower than $5 \%$. The data collected was statistically evaluated by of the Chi-squared test, mathematically written as:

$x^{2}=\sum_{i=1}^{k} \frac{\left(x_{i}-N p_{i}\right)^{2}}{N p_{i}}$

Where $\mathrm{x}$ is an observed frequency and $\mathrm{Np}$ is an expected frequency. When $p$-value $\leq \alpha, \mathrm{H}_{0}$ is rejected. When $p$-value $>\alpha, \mathrm{H}_{0}$ is confirmed.

An alternative test is the Fisher's exact test. When we represent the cells of matrix $2 \times 2$ by the letters $a, b, c$ and $d$, call the totals across rows and columns marginal totals, and represent the grand total by $n$. 


\begin{tabular}{|l|l|l|l|}
\hline Matrix $2 \times 2$ & & & Row Total \\
\hline & a & b & $a+b$ \\
\hline & c & d & $c+d$ \\
\hline Column Total & $a+c$ & $b+d$ & $a+b+c+d(=n)$ \\
\hline
\end{tabular}

The probability of obtaining such a set of values was given by the hypergeometric distribution:

$p=\frac{\left(\begin{array}{c}a+b \\ a\end{array}\right)\left(\begin{array}{c}c+d \\ c\end{array}\right)}{\left(\begin{array}{c}n \\ a+c\end{array}\right)}=\frac{\left(\begin{array}{c}a+b \\ b\end{array}\right)\left(\begin{array}{c}c+d \\ d\end{array}\right)}{\left(\begin{array}{c}n \\ b+d\end{array}\right)}=\frac{(a+b) !(c+d) !(a+c) !(b+d) !}{a ! b ! c ! d ! n !}$

where the binomial coefficient and the symbol! indicates the factorial operator.

The Fisher's exact test computes the probability of having the observed data (using the hypergeometric distribution) as well as the probabilities of getting all more extreme possible datasets under the null hypothesis. These probabilities are used to compute the Fisher's exact test p-value.

The difference between the Chi-square test and Fisher's exact test lies in the way how the p-value is computed. When theoretical frequencies include frequencies that are lower than 5 or when the dataset's marginal sums (sums per row or per column) are very uneven, it is better to rely on the Fisher's exact test. We use XLSTAT for Excel to calculate the Chi-square test and Fisher's exact test. Software XLSTAT displays the results associated with both mentioned tests for any matrix dimensions. For more information, see www.xlstat.com.

\section{EMPIRICAL RESULTS AND DISCUSSION}

The agile approach is a counterpart to the waterfall one. Even though agile methods are typical for software innovation in the future, it is expected that agile methods will be part of the creative project management (Dobson, 2010). When successful management of change is crucial to any organization in order to survive and succeed in the present highly competitive and continuously evolving business environment, one needs to know how to change effectively and when it is possible. In the research, there was indicated that there is still a predominance of knowledge and experience in waterfall methods, though the majority of responders had the experience in both methods, see Tab. 1. This should be explained by the fact that agile methods are relatively young and the majority of projects are still managed using the classic management style. Nevertheless, there is a clear trend that many project managers are learning both styles to be more flexible to the present requirements (almost 60\% of respondents).

Tab. 1 - Number of responses in management style experience. Source: own research

\begin{tabular}{|l|l|l|}
\hline \multicolumn{3}{|l|}{ Are you more experienced in } \\
\hline & Absolute & Percentage \\
\hline Agile & 10 & $8.4 \%$ \\
\hline Classic & 38 & $31.9 \%$ \\
\hline Both & 71 & $59.7 \%$ \\
\hline
\end{tabular}


As shown in Table 2, more than $80 \%$ of respondents agree that it is possible to change the management style of a certain project ("Maybe yes," "Yes"). Many respondents indicated valuable recommendations on how to undertake this change.

Tab. 2 - Number of responses: changing the project management style. Source: own research

\begin{tabular}{|l|l|l|}
\hline \multicolumn{3}{|c|}{ To change of the project management style during the project } \\
\hline & Absolute & Percentage \\
\hline Absolutely not & 5 & $4.2 \%$ \\
\hline Rather not & 17 & $14.3 \%$ \\
\hline Maybe yes & 16 & $13.4 \%$ \\
\hline Yes for some projects & 81 & $68.0 \%$ \\
\hline
\end{tabular}

The following represents the general recommendations were indicated:

- With extremely large delivery issues, the switch from waterfall to agile is very contributive.

- The organization must also have an agile mindset. The organization in which the project is implemented has a tremendous influence on the processes in the individual project. Therefore, it is very difficult to implement an agile project in a classical organization. The agile work form is not just a matter of methods, but also a matter of mindset and behavior. People do not change their mindset and behavior overnight.

- There must be knowledge of both the classical and agile style in the projects. If a company has the expertise to work in the traditional environment, and at the same time the project manager possess agile knowledge, it is possible to change the project management style during the course of the project.

- The possibility to switch between the classical and agile style depends on the phase of a project cycle. Initiation and closure will always have a waterfall style (to deal with clear objectives \& tangible results); whereas in the phase of execution, the agile style can be implemented in most projects.

- Culture and the nature of the projects play a role. Project execution goes hand in glove with the organizational culture and the nature of the project. For this reason a program maintains sub-projects executed through different methodologies to produce best results. The best way to achieve good results depends on the project manager and culture. Tailoring the activities to the project environment, i.e. not only the project management style, is important. Many other aspects including size, complexity, scope, and risk are very important for the success of a project.

- Agile is adaptable but must adhere to the main principles of project management. Selection of the right methodology for the project and industry sector at the start of the project is crucial to project success. The more project planning done in the initiation and planning phase and the right methodology selected, the greater likelihood the project will be a success. In the agile process, if the scope creep is evolving within the project parameters, then there is less likelihood the project manager is going to deliver the project objectives. Agile is most commonly used in the IT world and has had some success. 
- Some projects are better run with a combination of agile and waterfall. In the project planning process, if a project manager determines it better to use agile, he/she would switch processes to agile when appropriate.

- Switch only when needed. Waterfall and agile styles are two totally different worlds in project management. It is helpful to separate different parts of a waterfall project to executed in the agile style if needed. But attempting to execute parts of an agile plan in waterfall has been found to be ineffective and is not recommended.

- Adopting an agile requires a plan. There is a misunderstanding that agile can be "naturally" adopted, though in reality it necessitates a very structured transition plan: 1. a buy in from the sponsor, 2. a well-trained agile team (with no detractors) 3. a project that is realistic and feasible to build some confidence. 4 . a clear vision of why agile was chosen over waterfall; this is normally connected to an issue or shortcoming associated with waterfall, 5. Different cost considerations (an allocated budget per agile team, not per project) and perception of resources, e.g. people are not resources, but are individuals.

- It is recommended that the whole organization make the switch, which can be a painfully slow process. Shifting methodologies in the middle of a project would severely tax resources, schedule, budget, and quality. It's better to start fresh with a solid two- or three-year plan for making the transition. Major decision makers and all constituent/stakeholders need to be fully on board with at least $80 \%$ acceptance to support the development and leadership teams.

- Switching between the classical and agile style is more appropriate for large-scale projects. In case of large-scale and long-duration projects, during the initiation phase (when the initiation scales from 4 to 8 weeks or more), while progressively elaborating it could be identified that the chosen project management model may not work; in this case a project manager can take the initiative to switch and adopt the required process changes. For small-scale duration projects or projects with lower budgets, switching will certainly influence the cost.

- The agile style requires an independent budget. In some cases, it is better to initially allocate a portion of the project in line with agile methodology, but it is also important to follow up in greater detail regarding all costs, as it is quite easy to lose control of the project budget.

- In the digital world, change is inevitable and risk must be assessed. The project manager plays a crucial role. Striking a balance in regards to setting feasible expectations in terms of what is in scope and out of scope whilst trying to accommodate clients ever-changing needs/ requests is a must. Project managers play a big role in making sure that what is expected from the company he/she is working for is delivered to the satisfaction of the client. The project manager should be agile to an ever-changing environment.

To demonstrate the results of the Chi-square test and Fisher's exact tests, we prepared Table 3 and Figure 1, both of which contain a number of responses in regard to a change in project management style during the project. The table crosses two qualitative variables: "Experience in" (Agile, Classic, Both) and "It is possible to change the project management style." (Absolutely not, Rather Not, Maybe yes, Yes for some projects). The following table below contains data from the period Jul - Dec 2017, Jan - Aug 2018 and summarizes the data from these two periods in 2017 and 2018. 
Tab. 3 - Total number of responses collected in the years 2017 and 2018 Source: own research

\begin{tabular}{|c|c|c|c|c|c|c|c|c|c|}
\hline \multicolumn{10}{|c|}{ Possibility of the management style change } \\
\hline $\begin{array}{l}\text { Collecting } \\
\text { data: }\end{array}$ & \multicolumn{3}{|c|}{ Jun-Dec 2017} & \multicolumn{3}{|c|}{ Jan-Aug 2018} & \multicolumn{3}{|c|}{ Jul 2017 - Jun 2018} \\
\hline \multirow{2}{*}{$\begin{array}{l}\text { Observed } \\
\text { frequency }\end{array}$} & \multicolumn{3}{|c|}{ Experienced in } & \multicolumn{3}{|c|}{ Experienced in } & \multicolumn{3}{|c|}{ Experienced in } \\
\hline & Agile & Classic & Both & Agile & Classic & Both & Agile & Classic & Both \\
\hline $\begin{array}{l}\text { Absolutely } \\
\text { not }\end{array}$ & 1 & 0 & 0 & 2 & 1 & 1 & 3 & 1 & 1 \\
\hline Rather not & 1 & 2 & 4 & 2 & 1 & 7 & 3 & 3 & 11 \\
\hline Maybe yes & 1 & 2 & 3 & 2 & 2 & 6 & 3 & 4 & 9 \\
\hline $\begin{array}{l}\text { Yes for } \\
\text { some } \\
\text { projects }\end{array}$ & 0 & 11 & 18 & 1 & 19 & 32 & 1 & 30 & 50 \\
\hline
\end{tabular}

Looking at the results, we can see that project managers with agile-style management experience are of the opinion that a change is rather impossible. Project managers who are more experienced only in the waterfall management style are convinced that a change is possible for some projects, with the same result for project managers who are experienced in both management styles.

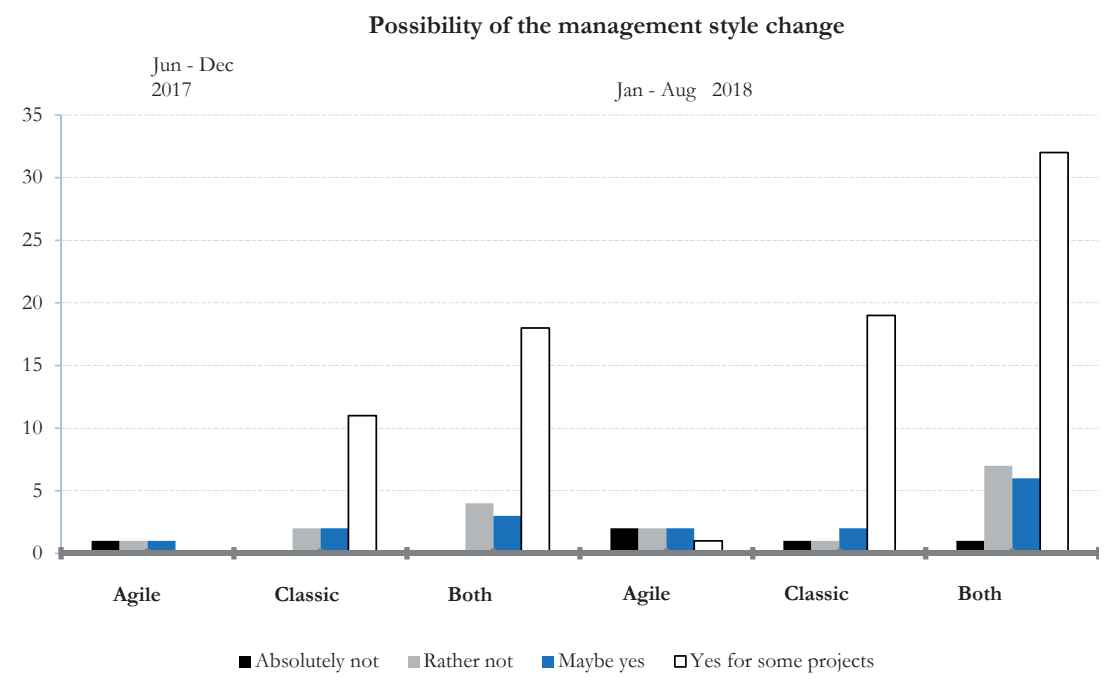

Fig. 1 - Bar graph for the corresponding data from 2017 and 2018. Source: own research using questionnaires

Considering the results of recommendations, we have to put forth the hypothesis: "Is a change in management style possible in the course of a project life cycle?". In Table 4, data have been collected first with the calculation of theoretical frequencies, and then in terms of the Chi-square test in the period 2017-2018 ( $\mathrm{N}=119)$. Note that five of the frequencies are lower than 5 in Table 4 , a result precluding the use of the Chi-square test for this data. 
Tab. 4 - Results: Theoretical frequencies for the Chi-square test. Source: own research

\begin{tabular}{|l|l|l|l|l|}
\hline \multirow{2}{*}{ Possibility of management style change } & \multirow{2}{*}{ Total } \\
\hline Absolutely not & \multicolumn{2}{l|}{ Experienced in } \\
\cline { 2 - 4 } & Agile & Classic & Both & \\
\hline Rather not & 3 & 1 & 1 & 5 \\
\hline Maybe yes & 3 & 3 & 11 & 17 \\
\hline Yes for some projects & 3 & 4 & 9 & 16 \\
\hline Total & 1 & 30 & 50 & 81 \\
\hline Theoretical frequencies & 10 & 38 & 71 & 119 \\
\hline Absolutely not & Agile & Classic & Both & Total \\
\hline Rather not & 0.42 & 1.60 & 2.98 & 5 \\
\hline Maybe yes & 1.43 & 5.43 & 10.14 & 17 \\
\hline Yes for some projects & 1.34 & 5.11 & 9.55 & 16 \\
\hline Total & 6.81 & 25.87 & 48.33 & 81 \\
\hline
\end{tabular}

The frequencies in responses for the managers with agile experience only is very low. For this reason, we merged responses for (Absolutely not, Rather not) as "Rather not" and also answers for (Maybe yes, Yes for some projects) as "Maybe yes" and thus were able to compile the data shown in Table 5. The acceptance of the correctness of our hypothesis increased in this case. Note that again one of the frequencies are lower than 5 (see Table 5), thus again precluding the use of the Chi-square test.

Tab. 5 - Results: simplified data for YES and NO answers. Source: own research

\begin{tabular}{|l|l|l|l|l|}
\hline \multirow{2}{*}{ Possibility of management style change } & \multirow{2}{*}{ Total } \\
\hline \multirow{2}{*}{ Observed frequencies } & \multicolumn{2}{|l|}{ Experienced in } & \\
\cline { 2 - 4 } & Agile & Classic & Both & \\
\hline Rather not & 6 & 4 & 12 & 22 \\
\hline Maybe yes & 4 & 34 & 59 & 97 \\
\hline Total & 10 & 38 & 71 & 119 \\
\hline Theoretical frequencies & Classic & Agile & Both & Total \\
\hline Rather not & 1.85 & 7.03 & 13.13 & 22 \\
\hline Maybe yes & 8.15 & 30.97 & 57.87 & 97 \\
\hline Total & 10 & 38 & 71 & 119 \\
\hline
\end{tabular}

In order to verify the hypotheses, we used the Fisher's exact test solely, the results of which were calculated using statistical software XLSTAT from Table 5. The results are displayed in the Table 6 below. 
Tab. 6 - Table results: Fisher's exact test with alpha 0,05. Source: own research using questionnaires

\begin{tabular}{|l|l|}
\hline & $2017-2018$ \\
\hline p-value (Two-tailed) & 0.005 \\
\hline alpha & 0.05 \\
\hline
\end{tabular}

According to the these results, we can conclude that a change in management style during the course of the project life cycle is possible. If we exclude the situations when the switch between the classical and agile approach is impossible (as stated in the Introduction and Literature Review), on the basis of the collected responses, it can be argued that a change in the management style during the course of a project cycle is indeed possible, and it is expected that this change will result in greater project success.

\section{CONCLUSION}

In this paper, we aimed to determine the possibility of changing the management style during the course of a project as well as to establish whether a change in the management style is possible during the course of a project life cycle. The research results have shown that a change in the management style is possible, and it is also expected that it will result in greater project success. Changing the management style during this period remains a debatable topic in the already existing research in the field. Despite the fact that the majority of responders agreed with the research aim, additional work should be done to identify what type of projects had greater success as well as how to undertake this change. The research in this topic is relatively recent, however, many considerations and practical applications have been made. By using the Fischer's exact test, in our case mostly from the management responses of small and medium-sized entrepreneurs, we have shown theoretically that it is feasible to change the management style of the project from the classic to the agile approach.

We assume that the number of responses in our next period of research will increase as well as the comments regarding projects during which the management style has been change to agile. Our research continues a discussion that could lead to guidelines that make it easier for project managers to move from classical to agile management.

In our further research, we will identify the risks and necessary measures for a change in management style from the classical to agile approaches in SME projects.

\section{References}

1. Agile Alliance. (2018). Manifesto for Agile Software Development. Agile Alliance. Corryton (USA): Agile Alliance, 2018. Available from https://www.agilealliance.org/agile101/theagile-manifesto/

2. Bennebroek, G. K. M., \& Veld, R. J. (2004). Methodologies for co-creating change: The power of interaction and collaboration. Dynamics of organizational change and learning, pp. $317-341$. 
3. Bentley, C. (2010). The Essence of the Project Management Method PRINCE2. Trade Mark of the Cabinet Office. England. Protec.

4. Boonstra, J. J. (2004). Dynamics of Organizational Change and Learning. Chichester (England): John Wiley \& Sons.

5. Brightman, B. K., \& Moran, J. W. (2001). Managing organizational priorities. Career Development International, 6 (5), 244-288.

6. Burnes, B., \& Jackson, P. (2011). Success and failure in organizational change: An exploration of the role of values. Journal of Change Management, 11 (2), 133-162.

7. Chin, G. (2004). Agile Project Management: How to Succeed in the Face of Changing Project Requirements. New York: AMACOM.

8. Cummings, J. N. (2004). Work Groups, Structural Diversity, and Knowledge Sharing Global Organization. Management Science, 50 (3), 352-364.

9. De Witt, B. (2017). Strategy: An International Perspective. Cengage Learning. 6th Edition.

10. Dobson, M. (2010). Creative Project Management. Innovative Project Options to solve Problems on Time and Under Budget. McGraw - Hill Education: USA.

11. Hayes, J. (2014). The theory and practice of change management. Palgrave: Macmillan.

12. Hsieh, T. Y., Lu, S. T., \& Wu, C. H. (2004). Statistical analysis of causes for change orders in metropolitan public works. International Journal of Project Management, 22 (8), 679-686.

13. Hughes, M. (2011). Do 70 percent of all organizational change initiatives really fail? Journal of Change Management, 11 (4), 451-464.

14. IPMA. (2006). Competence Baseline for Project Management. Version 3.0. The Netherlands: International Project Management Association.

15. ISO. (2012). ISO 21500: 2012 (E) Guidance on Project Management, International Organization for Standardization.

16. Jashapara, A. (2004). Knowledge Management: An Integrated Approach. FT Prentice Hall. Essex.

17. Kaliprasad, M. (2005). Agile project management: How to succeed in the face of changing project requirements. Cost Engineering (Morgantown, West Virginia), 47 (10), 1-29.

18. Kerzner, H. (2004). Advanced Project Management. Hoboken, New Jersey, USA: John Wiley \& Sons, Inc.

19. Ključnikov, A., Belás, J., \& Smrčka, L. (2016). The role of risk-taking and competitive aggressiveness in management of SMEs. Polish Journal of Management Studies, 14 (1), 129-139. https://doi.org/10.17512/pjms.2016.14.1.12

20. Kotter, J. P., \& Schlesinger, L. A. (2008). Choosing strategies for change. Harvard business review.

21. Lavazza, L., \& Valetto, G. (2000). Enhancing requirements and change management through process modeling and measurement. In Requirements Engineering 2000. Proceedings. 4th International Conference on Requirements Engineering (pp. 106-115). IEEE. 
22. Lechler, T. G., \& Cohen, M. (2009). Exploring the role of steering committees in realizing value from project management. Project Management Journal, 40 (1), 42-54.

23. Machal, P., Ondrouchova, M., \& Hvizdova, E. (2017). Novéperspektivy v projektovém managementu. Brno: Vydavatelství Mendelovy university v Brně.

24. Meding, W. (2017). Effective monitoring of progress of agile software development teams in modern software companies - an industrial case study. ACM International Conference Proceeding Series 2017 (pp. 23-32).

25. Mir, F. A., \& Pinnington, A. H. (2014). Exploring the value of project management: Linking Project Management Performance and Project Success. International Journal of Project Management, 21 (5), 209-213.

26. Norman, G. (2010). Likert scales, levels of measurement and the "laws" of statistics. Advances in bealth sciences education, 15 (5), 625-632.

27. Orłowski, C., Deręgowski, T., Kurzawski, M., \& Ziółkowski, A. (2017). Evaluation of readiness of IT organizations to agile transformation based on a case-based reasoning. https://doi. org/:10.1007/978-3-319-54430-4_75

28. Paredes, J., Anslow, C., \& Maurer, F. (2014). Information visualization for agile software development. Paper presented at the Proceedings - 2nd IEEE Working Conference on Software Visualization, VISSOFT 2014, 157-166. https://doi.org/10.1109/VISSOFT.2014.32

29. PMI. (2011). Practice Standard for Work Breakdown Structures - Second Edition. Newtown Square: Project management institute, 2011.

30. PMI. (2013). A guide to the project management body of knowledge. PMBOK® guide. 5th ed. Newtown Square: Project management institute, 2013.

31. Rajnoha, R., Galova, K., \& Rozsa, Z. (2018). Measurement of impact of selected industrial engineering practices on companies' economic performance. Engineering Economics, 29 (2), 176-187. https://doi.org/10.5755/j01.ee.29.2.19871

32. Saito, S., Iimura, Y., Massey, A. K., \& Antón, A. I. (2018). Discovering undocumented knowledge through visualization of agile software development activities: Case studies on industrial projects using issue tracking system and version control system. Requirements Engineering, pp. 1-19. https://doi.org/10.1007/s00766-018-0291-4

33. Thiemich, C., \& Puhlmann, F. (2013). An agile BPM project methodology. https://doi. org/10.1007/978-3-642-40176-3_25

34. Todnem, R. (2007). Organizational change management: A critical review. Journal of Change Management, 5(4), 369-380, https://doi.org/10.1080/14697010500359250

35. Tomanek, M., Cermak, R., \& Smutny, Z., (2014). Conceptual Framework for WEB Development Projects Based on Project Management and Agile Development Principles. In V. Grozdanic (Ed.) Proceedings of the 10th European Conference on Management Leadership and Governance. (pp. 550-558), Zagreb (Croatia): ECMLG 2014.

36. Thomas, J., \& Mullaly, M. (2007). Understanding the Value of Project Management: First Steps on an International Investigation in Search of Value. Project Management Journal, 38, 74-89. 
37. Too, E. G., \& Weaver, P. (2013). The management of project management: A conceptual framework for project governance. International Journal of Project Management, 1-13. Available from http://www.mosaicprojects.com.au/PDF_Papers/P162_The_Management_of_ Project_Management_IJPM.pdf.

38. Winter, M., \& Szczepanek, T. (2008). Projects and programmes as value creation processes: A new perspective and some practical implications. International Journal of Project Management, 26, 95-103.

\section{Contact information}

Ing. Branislav Gablas

Pan-European University

Faculty of Economics and Entrepreneurship

Department of Management and Marketing

Slovak Republic

E-mail:Branislav.gablas@gmail.com

assoc. prof. Eugen Ruiicky, PhD.

Pan-European University

Faculty of Informatics

Department of Applied Informatics

Slovak Republic

E-mail:eugen.ruzicky@paneurouni.com

ORCID: 0000-0001-7940-3782

Ing. Martina Ondrouchova, PhD

Independent researcher

Slovak Republic

E-mail:ondrouchovam@email.cr. 